1

2

3

4

5

6

$7 \quad{ }^{1}$ Department of Drug Delivery (DDEL), Helmholtz-Institute for Pharmaceutical

8 Research Saarland (HIPS), Helmholtz Centre for Infection Research (HZI), Saarland

9 University, 66123 Saarbrücken, Germany

10

11

12

13

14

15

16

17 * Corresponding author: Helmholtz Institute for Pharmaceutical Research Saarland

\section{INHALABLE CLARITHROMYCIN MICROPARTICLES FOR TREATMENT OF}

\section{RESPIRATORY INFECTIONS}

Frantiescoli Dimer ${ }^{1}$; Cristiane de Souza Carvalho-Wodarz ${ }^{1}$; Jörg Haupenthal ${ }^{2}$; Rolf Hartmann ${ }^{2,3}$; Claus-Michael Lehr ${ }^{1,3^{*}}$

${ }^{2}$ Department of Drug Development and Optimization (DDOP), Helmholtz-Institute for

Pharmaceutical Research Saarland (HIPS), Helmholtz Centre for Infection Research

(HZI), Saarland University, 66123 Saarbru $\square$ cken, Germany

${ }^{3}$ Biopharmacy and Pharmaceutical Technology, Department of Pharmacy, Saarland University, Saarbrücken, Germany

(HIPS), Department of Drug Delivery (DDEL), Saarland University, P.O. Box 151150 , 66041, Saarbrücken, Germany. Tel.: +49 681302 3039; fax: + 496813024677.

E-mail address: claus-michael.lehr@helmholtz-hzi.de

\section{ABSTRACT}

Purpose The aim of this work was to develop clarithromycin microparticles (CLARI-

MP) and evaluate the aerodynamic behavior, safety in bronchial cells and anti-bacterial efficacy.

Methods Microparticles containing clarithromycin were prepared as dry powder carrier for inhalation, using leucine and chitosan. CLARI-MPs were deposited on Calu-3 grown at air-interface condition, using the pharmaceutical aerosol deposition device on cell 
29 cultures (PADDOCC). Deposition efficacy, transport across the cells and cytotoxicity

30 were determined. Anti-antibacterial effect was evaluated against Pseudomonas

31 aeruginosa, Escherichia coli and Staphylococcus aureus.

32 Results Microparticles were of spherical shape, smooth surface and size of about 765

$33 \mathrm{~nm}$. Aerosolization performance showed a fine particle fraction (FPF) of $73.3 \%$, and a

34 mass median aerodynamic diameter (MMAD) of $1.8 \mu \mathrm{m}$. Deposition on Calu-3 cells

35 using the PADDOCC showed that $8.7 \mu \mathrm{g} / \mathrm{cm}^{2}$ of deposited powder were transported to

36 the basolateral compartment after $24 \mathrm{~h}$. The safety of this formulation is supported by

37 the integrity of the cellular epithelial barrier and absence of toxicity. Clarithromycin

38 microparticles maintained their antimicrobial efficacy against Gram positive and Gram

39 negative bacteria.

40 Conclusions The appropriate aerodynamic properties and the excellent deposition on

41 Calu-3 cells indicate that clarithromycin microparticles are suitable for administration

42 via pulmonary route and are efficient to inhibit bacteria proliferation.

43

44 KEY WORDS

45 Aerosol; Dry Powder Inhaler; Lung infection; Safety

46

47 RUNNING HEAD

48 Clarithromycin microparticles for respiratory infections

49

50 ABBREVIATIONS

51 CLARI - Clarithromycin

52 CLARI-MPs - Clarithromycin microparticles

53 DPI - dry powder inhalers

54 DSC - differential scanning calorimetry

55 ED - emitted dose

56 FPF - fine particle fraction 
57 IS - internal standard

58 LC-MS/MS - liquid chromatography - tandem mass spectrometry

59 MIC - minimal inhibitory concentration

60 MMAD - mass median aerodynamic diameter

61 NGI - next-generation pharmaceutical impactor

62 PADDOCC - pharmaceutical aerosol deposition device on cell cultures

$63 \mathrm{PM}-$ physical mixture

$64 \mathrm{RI}$ - respiratory infection

65 SEM - scanning electron microscopy

66 TEER - transepithelial electrical resistance

67

\section{INTRODUCTION}

69 Respiratory infections (RI) have been treated since long time with antibiotics. Despite 70 of the great progress of antimicrobial agents in the last century, it is still a challenge to 71 treat bacterial infection, mainly due to the development of resistance. Traditionally, the 72 treatment of $\mathrm{RI}$ consists on high doses of single or combined antibiotics administered by oral or intravenous route, which induce undesirable side effects mainly due to high systemic bioavailability. To overcome this and improve the efficacy of RI therapy, the inhalation route has been used with pressurized metered dose inhalers (pMDIs), nebulizers and dry powder inhalers (DPI) (1-4). Inhalation route has several advantages including: rapid onset of action (2), high drug amount targeted to the lungs $(1,5)$, lower systemic bioavailability leading to a decrease of both, side effects $(6)$ and drug resistance build-up (7). However, DPI devices have some advantages over other methods of pulmonary drug delivery, such as the direct delivery of drug into the deep lungs utilizing the patient's breathing.

82 Among several methods available to produce inhalable particles as DPI, spray drying is 83 one of the most used. Spray drying is performed in a one-step process, and according 84 to the materials and conditions used (8) it is possible to produce dry powder particles 
with specific and controlled characteristics (such as particle size, size distribution and particle surface morphology). The particles properties might have direct influence on the aerosol properties of DPI formulation and consequently on the DPI deposition in the respiratory tract $(9)$.

Nevertheless, the safety and efficacy of new DPI formulations must always be tested to predict their effects on the body before clinical use. Moreover, deposition in vitro should considerer the physiological condition in vivo. Thereby Hein et al. developed a device called Pharmaceutical Aerosol Deposition Device on Cell Cultures (PADDOCC), which allows studying the DPI deposition and absorption in pulmonary epithelial cells (10). This system avoids the cell damage caused by turbulences of air streams as shown for example with electrostatic precipitation (11). Moreover, the PADDOCC use the sedimentation process, that is the mainly deposition mechanism in the deep lung, while twin stage impinger (TSI), multistage liquid impinger (MSLI) and anderson cascade impactor $(\mathrm{ACl})$ rely on deposition by impaction $(4,12-14)$.

Tobramycin is the only antibiotic available in the market as DPI (15), but others antibiotics are under investigation to be also used as DPI for the treatment of Rl; these include aminoglycosides, fluoroquinolones, glycopeptides, macrolides, monolactams and polypeptides (16).

Clarithromycin (CLARI) is a hydrophobic macrolide, which is known by its bacteriostatic action and the anti-inflammatory effect $(17,18)$. Macrolides bind reversibly to domain $\mathrm{V}$ of $23 \mathrm{~S}$ ribosomal RNA ( $\mathrm{rRNA}$ ) in the 50 s subunit of the bacterial ribosome, inhibiting RNA-dependent protein synthesis (18). CLARI together with its active metabolite, 14hydroxyclarithromycin, are responsible for enhanced antimicrobial activity against respiratory pathogens such as Staphylococcus aureus, Pseudomonas aeruginosa, Streptococcus pneumoniae, Escherichia coli, Mycobacteria smegmatis and Haemophilus influenza (18). Despite been used to that broad pathogen spectrum, several problems are reported with CLARI treatment, mainly due to its low oral bioavailability (55\%), side effects (gastrointestinal disturbs, hepatotoxicity and renal 
113 tubular degeneration) and pathogen resistance caused by the high antibiotic doses

114 administered $(19,20)$. The administration of clarithromycin as DPI could improve the

115 antimicrobial activity and overcome adverse effect, reaching thus a better patient

116 compliance. Some works have been done towards to develop DPI-CLARI. Park and

117 coworkers already developed a DPI-CLARI formulation with excellent aerosol

118 performance (1). Moreover, Moghaddam increased the yield and fine powder fraction

119 (FPF) with the addition of leucine in a new PLGA-clarithromycin formulation (21).

120 However, these papers did not test the efficacy of the formulations against respiratory

121 pathogens and the safety in pulmonary cells. Recently, Haghi et al. developed a

122 clarithromycin as pMDIs intended for anti-inflammatory therapy, with beneficial effects

123 on cell barrier integrity, regulation of anti-inflammatory cytokine (IL-8) and inhibition of

124 mucus production after deposition of Clarithromycin at low concentration on Calu-3

125 cells (4). The administration of clarithromycin, a hydrophobic drug, as pMDIs or

126 nebulizers needs to use solvents to solubilize it, while DPI will avoid solvent exposition.

127 Therefore the aim of this work was to explore clarithromycin-microparticles as DPI,

128 using chitosan as mucoadhesive and L-leucine as carrier in order to extend the lung

129 residence time and improve the yield and FPF, respectively. For this purpose, we

130 evaluated microparticle characteristics, in vitro aerosolization performance, in vitro

131 deposition on Calu-3 cells using the Pharmaceutical Aerosol Deposition Device on Cell

132 Cultures (PADDOCC) and their effect on the growth of Escherichia coli, Pseudomonas

133 aeruginosa and Staphylococcus aureus.

134

135 MATERIALS AND METHODS

136 Materials

137 Clarithromycin, L-leucine, ammonium acetate, amitriptyline, dimethyl sulfoxide

138 (DMSO), sigmacote, sodium pyruvate and 3-(4,5- dimethylthiazol-2-yl)-2,5-

139 diphenyltetrazolium bromide (MTT) were purchased from Sigma-Aldrich Co. (St. Louis, 
140 USA). Ultrapure chitosan chloride Protasan UP CL113 with a molecular weight of 50-

$141150 \mathrm{kDa}$ and a degree of deacetylation between $75 \%$ and $90 \%$ was purchased from

142 NovaMatrix (FMC Bio-Polymer, Drammen, Norway). Calu-3 cells (HTB-55) were

143 obtained from the DSMZ GmbH (Braunschweig, Germany). Minimum essential medium

144 (MEM) containing Earl's Salts and L-glutamine was bought from Gibco (Life

145 Technologies, Paisley, UK). Fetal calf serum (FCS) was bought from Lonza (Vervieers,

146 Belgium), and Nonessential amino acid (NEAA) solution from GE Healthcare (PAA

147 laboratories, Pasching, Austria). Methanol, ethanol and all other chemicals and

148 solvents used were analytical grade. Purified water was produced by Milli-Q water

149 purification system (Merk Millipore, Billerica, USA).

150

151

CLARI loaded microparticles

152

Initially, $0.05 \mathrm{~g}$ of Leucine and $0.05 \mathrm{~g}$ of chitosan were solubilized in $25 \mathrm{~mL}$ of water at room temperature by controlled magnetic stirring. Separately, $0.05 \mathrm{~g}$ of CLARI was dissolved in $5 \mathrm{~mL}$ of ethanol. After both phases were completely dissolved, they were mixed under moderate magnetic stirring at room temperature during 15 minutes. The solution was atomized with the Nano Spray Dryer B-90 (Büchi Labortechnik AG,

157 Switzerland). The equipment was maintained in open mode configuration using the following parameters: pump mode 2 with $80 \%$ of spray rate, airflow of $120 \pm 5 \mathrm{~L} / \mathrm{min}$, inlet temperature of $80^{\circ} \mathrm{C}$ and spray mesh with aperture size of $4.0 \mu \mathrm{m}$. The separation of Clarithromycin microparticles (CLARI-MPs) from particle-collecting electrode were carried-out with a soft brush.

\section{Spray-dried powder characterization}

Yield and Drug content

165 The yield was determined through the related amount of powder obtained in the initial concentration of all materials used in the solution. The clarithromycin content was 
167 quantified by liquid chromatography - tandem mass spectrometry (LC-MS/MS) method 168 as described above.

\section{LC-MS/MS Method}

171 Clarithromycin quantification was carried out using a LC-MS/MS technique based on a 172 previously validated method (22). This system consists of a TSQ Quantum ${ }^{\circledR}$ Access 173 MAX Triple Quadrupole Mass Spectrometer (Thermo Fisher Scientific, San Jose, USA) 174 equipped with an Accela 1250 pump, Accela Autosampler, and the TSQ Quantum. 175 CLARI separation was made with an Accucore RP-MS column (150 mm x $2.1 \mathrm{~mm}, 2.6$ $176 \mu \mathrm{m}$, Thermo Fisher Scientific, San Jose, USA) kept at $30^{\circ} \mathrm{C}$. The isocratic mobile 177 phase consisted of $70 \%$ of methanol containing $0.1 \%$ of formic acid $(\mathrm{v} / \mathrm{v})$ and $30 \%$ of ammonium acetate buffer $(5 \mathrm{mM})$ containing $0.1 \%$ of formic acid $(\mathrm{v} / \mathrm{v})$ was eluted at a

179 flow rate of $0.25 \mathrm{~mL} / \mathrm{min}$ during $4 \mathrm{~min}$. We used the Mass Spectrometry conditions:

180 heated electrospray ionization source (HESI-II), positive mode; sheath gas, nitrogen at 181 a flow rate of 35 arbitrary units; collision gas, argon; vaporizer temperature, $300^{\circ} \mathrm{C}$; ion 182 transfer capillary temperature, $250^{\circ} \mathrm{C}$; skimmer offset, $0 \mathrm{~V}$; spray voltage, $4000 \mathrm{~V}$. The 183 mass spectrometer was operated in the high-resolution selected reaction monitoring 184 (H-SRM) mode. The precursor ion transition of CLARI at $\mathrm{m} / \mathrm{z} 748.343$ to ion $\mathrm{at} \mathrm{m} / \mathrm{z}$ 185 (v. 2.2, San Jose, USA) with the settings as follows: peak detection algorithm, ICIS; smoothing points, 5; baseline window, 80; area noise factor, 5; peak noise factor, 10. Briefly, $100 \mu \mathrm{L}$ of samples were extracted with $0.9 \mathrm{~mL}$ of methanol:water $(1: 1, \mathrm{v} / \mathrm{v})$ containing the IS $(500 \mathrm{ng} / \mathrm{mL})$ under ultra sonication for 10 minutes. The samples were centrifuged (10000 g, $10 \mathrm{~min})$ and the supernatant (5 $\mu \mathrm{L})$ was injected using partial 
195 loop injection mode in the LC-MS/MS system. The developed method was linear on the

196 concentration range of $5-500 \mathrm{ng} / \mathrm{mL}\left(R^{2}=0.99\right)$.

197

198

Scanning Electron Microscopy

199

Morphology and particle size analysis of CLARI-MPs were evaluated with scanning

200

electron microscopy (SEM, Zeiss EVO HD15, Oberkochen, Germany). Samples of

201

CLARI-MPs were added in aluminum stubs with carbon conductive double-sided tape

202

and sputter-coated with a $10 \mathrm{~nm}$ layer of gold (Quorum Q150R ES, Ashford, UK).

203

Analyses were conducted under high vacuum conditions at an acceleration voltage of

$10 \mathrm{kV}$. Particle size distribution was analyzed using the software ImageJ (version

$1.47 \mathrm{v}$, National Institute of Health, USA) and it is expressed as the mean diameter \pm

206

standard deviation.

207

208

Differential Scanning Calorimetry (DSC)

209

Thermal analysis of pure raw materials, their physical mixture and the microparticle

210

developed were performed using differential scanning calorimetry (DSC) TA Q100 (TA

211

Instruments, New Castle, USA). The physical mixture was prepared using the same

212

amounts of each component and it was mixed with a pestle and a mortar.

213 Approximately $5 \mathrm{mg}$ of samples were placed on aluminum pans, hermetic sealed and

214 heated from 20 to $350{ }^{\circ} \mathrm{C}$ with a scan rate of $10^{\circ} \mathrm{C} / \mathrm{min}$ under a nitrogen atmosphere of

$21510 \mathrm{~mL} / \mathrm{min}$. DSC heating curves were analyzed using Universal Analysis 2000 software

216 (Version 4.5a, TA Instruments, New Castle, USA).

\section{Dissolution}

219 The dissolution of CLARI-MP was performed in a dissolutor Sotax AT6 (Sotax AG,

220 Basel, Switzerland). Approximately $6 \mathrm{mg}$ of the powder CLARI-MP (containing about 2

$221 \mathrm{mg}$ of CLARI) were filled in hypromellose capsule (size $n^{\circ} 3$ ). In order to compare the

222 dissolution of CLARI, it was also determined the dissolution of CLARI raw material (2 
$223 \mathrm{mg}$ ) with a paddle speed of $100 \mathrm{rpm}$, The sink conditions was maintained employing

$2241000 \mathrm{~mL}$ of phosphate buffer medium with $\mathrm{pH}=7.4$ and temperature of $37 \pm 1{ }^{\circ} \mathrm{C}$.

225 Samples $(1 \mathrm{~mL})$ were withdrawn at predetermined time points at 15, 30, 45, 60, 90 and

$226120 \mathrm{~min}$. The samples $(0.1 \mathrm{~mL})$ were diluted with $0.9 \mathrm{~mL}$ of methanol:water $(1: 1)$

227 containing the IS and filtered through $0.45 \mu \mathrm{m}$ and analyzed in the LC-MS/MS, as

228 described before. The dissolution of $50 \%$ of the drug for both formulations was

229 obtained from the release profiles fitted according to the first-order $\left(C=C_{0} \cdot e^{-k t}\right)$

230 mathematical model. Where $\mathrm{k}$ and $\mathrm{C}_{0}$ are the apparent kinetic rate constant and the

231 initial drug concentration at time $t(h)$, respectively.

232

\section{Aerodynamic particle analysis}

The aerodynamic particle size distribution of CLARI-MP was determined with the nextgeneration pharmaceutical impactor (NGI) (Copley Scientific, Nottingham, UK), set at a flow rate of $60 \mathrm{~L} / \mathrm{min}$ from a pump (HCP5 High Capacity Pump, Copley Scientific, Nottingham, UK) with the critical flow controller TPK (Copley Scientific, UK). The equipment was previously calibrated with a flow meter DFM3 (Copley Scientific, Nottingham, UK). The NGI was fitted with the USP throat and its appropriate preseparator. The effective cut-off diameters of stages $1,2,3,4,5,6$ and 7 at $60 \mathrm{~L} / \mathrm{min}$ flow rate were $8.06,4.46,2.82,1.66,0.94,0.55$ and $0.34 \mu \mathrm{m}$, respectively. Before the experiment, the NGI collection cups were coated with Sigmacote in order to avoid bias from particle bounce and re-entrainment within the impactor. CLARI-MP powder was accurately weighed (about $6 \mathrm{mg}$ ) into size $\mathrm{n}^{\circ} 3$ hypromellose capsules and loaded into a HandiHaler ${ }^{\circledR}$ dry powder inhaler (Boehringer, Ingelheim, Germany). After the capsule was perforated, the powder was released into the NGI for $4 \mathrm{sec}$ at $60 \mathrm{~L} / \mathrm{min}$. The particles retained in the inhalation device, mouthpiece adaptor, throat device, preseparator and each stage from one to eight were removed with 1:1 (methanol-water) solution and collected into volumetric flasks. The samples $(0.1 \mathrm{~mL})$ were diluted with 
251 in the LC-MS/MS for analysis. The emitted dose (ED) was calculated from the

252 proportion of drug that entered in the NGI compared to the total drug present in each capsule. The fine particle fraction (FPF), which is the percentage of particles with aerodynamic diameter lower than $5 \mu \mathrm{m}$, was determined from the sum of the stages 2 of the filter of the NGI.

Particle Size Distribution

The mass median aerodynamic diameter (MMAD) and the geometric standard deviation (GSD) were determined with the NGI data based on the cumulative particle size distribution functions. MMAD is defined as the diameter above and below which lies $50 \%$ of the mass of the particles. While GSD, a dimensionless number, is equal to the ratio between the MMAD and either $84 \%$ or $16 \%$ of the diameter size distribution.

263 The GSD, together with the MMAD, describe the particle size distribution of the 264 formulation.

\section{In Vitro Deposition Study}

Cell Culture

Calu-3 cells (HTB-55) were used between passage 30 and 42 . The cells were cultivated in $75 \mathrm{~cm}^{2}$ flasks in MEM supplemented with Earl's Salts and L-glutamine supplemented with $10 \%$ fetal calf serum (FCS), $1 \%$ non-essential amino acid (NEAA), $50 \mathrm{mM}$ sodium pyruvate, 100 units $/ \mathrm{mL}$ penicillin and $100 \mu \mathrm{g} / \mathrm{mL}$ streptomycin. The cells were incubated at $37{ }^{\circ} \mathrm{C}, 5 \% \mathrm{CO}_{2}$ and $95 \%$ humidity. Once reached confluence Calu-3 were detached with Trypsin and seeded in a 12 well Snapwells polyester inserts (1.12 $\mathrm{cm}^{2}, 0.4 \mu \mathrm{m}$ pore size, Corning Costar, Lowell, MA, USA) at $1.33 \times 10^{5} \mathrm{cells} / \mathrm{cm}^{2}$ concentration. After 48h, the cells were cultivated at air-liquid interfaced (ALI) by removing the apical medium and feeding only the basolateral part with $1.0 \mathrm{~mL}$ of complete MEM. ALI cultures were grown for 12-14 days, in order to differentiate and perform ideal epithelial barriers (23). 


\section{Pharmaceutical Aerosol Deposition Device on Cell Cultures (PADDOCC)}

Deposition experiments were performed with PADDOCC, as previously described by

Hein et al. $(10,24)$. Briefly, it consists of an airflow control unit $\left(\right.$ Akita $^{\circledR}$, Activaero,

Gemünden/Wohra, Germany), an aerosolization unit and a deposition unit, which are

all connected by silicon tubes. The PADDOCC (without the air flow control unit) was

accommodated in an incubator at $37^{\circ} \mathrm{C}$ and the following airflow parameters were used: dispersion impulse of $60 \mathrm{~L} / \mathrm{min}$ for $0.2 \mathrm{~s}$ and a ventilation flow of $6 \mathrm{~L} / \mathrm{min}$ for $2.0 \mathrm{~s}$.

\section{CLARI deposition}

To evaluate the total deposition of clarithromycin, a dry powder capsule with approximately $6 \mathrm{mg}$ of CLARI-MPs was aerosolized with the PADDOCC and deposited in sampling wells (i.e. without cells) with $0.5 \mathrm{~mL}$ of methanol:water (1:1). After three aerosolization-deposition cycles of 10 minutes, each well of the sampling unit was washed with $0.5 \mathrm{~mL}$ of methanol:water (1:1) and quantified by LC-MS/MS analytic method, as previously described.

\section{Permeability}

297 Firstly, the Snapwells ${ }^{\circledR}$ were placed into the sampling wells of the PADDOCC with 0.5 $\mathrm{mL}$ of MEM at $37^{\circ} \mathrm{C}$ in the basolateral compartment and were pre-equilibrated for 15 minutes. Then, the system was set up for three deposition cycles resulting in 30 min for aerosolization and deposition process. After this period, Snapwells ${ }^{\circledR}$ containing the cells were placed in a cell culture plate, and $1.5 \mathrm{~mL}$ of cell culture medium was added in the basolateral compartment. The cells were incubated at $37{ }^{\circ} \mathrm{C}, 5 \% \mathrm{CO}_{2}$ and $95 \%$ humidity with a rotational shaker at $150 \mathrm{rpm}$. Samples of $100 \mu \mathrm{L}$ were acquired each 30 minutes during 4 hours and at $24 \mathrm{~h}$ from the basolateral compartment to evaluate the formulation permeability across Calu-3. To analyze drug concentration, samples were extracted with methanol:water (1:1) containing the IS, centrifuged at $10.000 \mathrm{~g}$ for 
30710 min at $12{ }^{\circ} \mathrm{C}$ and the supernatants quantified by LC-MS/MS analysis. After the

308 permeability experiments, TEER values were measured to verify the integrity of cell

309 monolayer as mentioned below.

310

311 TEER Values

312 Transepithelial electrical resistance (TEER) was measured before and after the

313 permeability experiment to monitor cellular barrier integrity using a Volt-Ohm Meter

314 (EVOM with STX-2 chopstick electrodes, World Precision Instruments, Berlin,

315 Germany). Briefly, pre-warmed cell culture medium was added in the apical

316 compartment $(0.5 \mathrm{~mL})$ and in the basolateral compartment $(1.5 \mathrm{~mL})$ before TEER

317 measurement and incubated for $30 \mathrm{~min}$. The electrical resistance of insert membranes

318 without cells $(120 \Omega)$ was subtracted from all samples, and the resistance values were

319 multiplied by the surface area of the inserts $\left(1.12 \mathrm{~cm}^{2}\right)$.

320

321 Cell viability

322 Cell viability of CLARI-MPs was determined by MTT [(3-(4,5- dimethylthiazol-2-yl)-2,5-

323 diphenyltetrazolium bromide] assay. After 24 hours of the aerosolization and deposition

324 process with the PADDOCC system, the cells were washed with PBS and $5 \mathrm{mg} / \mathrm{mL}$

325 MTT solution in PBS pH 7.4 were added to each well. After 4h incubation, the cells

326 were lysed with DMSO and the formation of blue formazan crystals evaluated by

327 measuring absorbance at $550 \mathrm{~nm}$ with the plate reader Infinite M200 PRO (Tecan,

328 Grödig, Austria). Untreated cells and cells incubated with Triton X-100 1\% were used

329 as negative and positive controls, respectively.

330

$331 \quad$ Antibacterial studies

332

333

Minimal Inhibitory Concentration (MIC) assays 
MIC50 values were determined in Pseudomonas aeruginosa PA14, Escherichia coli

K12 and Staphylococcus aureus subsp. aureus (Newman strain) and were performed as described recently (25), with slight modifications. Stock test formulations of 2 $\mathrm{mg} / \mathrm{mL}$ were prepared, while CLARI was dissolved in DMSO (maximal DMSO concentration in the experiment: $1 \%$ ), CLARI-MP was dispersed in water. Final concentrations of the test formulations were obtained ranging from 0.02 to $20 \mu \mathrm{g} / \mathrm{mL}$. The optical density (OD) was determined after addition of formulations and again after incubation for $18 \mathrm{~h}$ at $37^{\circ} \mathrm{C}$ and $50 \mathrm{rpm}$ (200 rpm for $P$. aeruginosa) in 96 well plates (Sarstedt, Nümbrecht, Germany) using a FLUOStar Omega (BMG labtech, Ortenberg, Germany). Given MIC50 values are means of three independent determinations and are defined as the concentration of compounds that reduced the OD600 by $50 \%$.

\section{Bacteria Scanning Electron Microscopy}

The interactions between the bacteria ( $S$. aureus or $P$. aeruginosa) with CLARI-MPs or CLARI were visualized with SEM. For that the samples were previously fixed with $1.0 \%$ glutaraldehyde in $0.2 \mathrm{M}$ hepes buffer $(\mathrm{pH} 7.4)$, dehydrated in a graded ethanol series (from $30 \%$ to $100 \%$ ) and finally dried by evaporation with hexamethyldisilazane. The specimens were mounted on stubs and sputtered with gold to a layer thickness of 10 nm (Quorum Q150R ES, Ashford, UK) and observed at $5 \mathrm{kV}$ under high vacuum conditions on a Zeiss EVO HD15 SEM (Zeiss, Oberkochen, Germany).

\section{Data Analysis}

The experiments values were expressed as means \pm standard deviation (S.D.). Data were subjected to statistical analysis using the software package Prism 6 (GraphPad Prism, San Diego, USA). The significance were analyzed by $t$-test. Difference was considered statistically significant when $p<0.05$.

\section{RESULTS}


362

363

364

365

366

367

368

369

370

371

372

373

374

375

376

377

378

379

380

381

382

\section{Microparticles characterization}

CLARI-loaded microparticles as DPI were developed and evaluated regarding cell interaction and anti-microbial activity. A DPI formulation containing clarithromycin microparticles was produced by spray drying technique using the Nano Spray Dryer Buchi $\mathrm{B}-90^{\circledR}$, with a yield of $60.7 \pm 2.3 \%$. The obtained powder had a drug loading of $36.0 \pm 1.4 \%(\mathrm{~m} / \mathrm{m})$. Microparticles were nearly spherical, showed a smooth surface with some holes and were not agglomerated (Fig 1). Particle size of the powders ranged from approximately 0.3 to $2.5 \mu \mathrm{m}$ with an average of $765 \pm 358 \mathrm{~nm}$ (data not shown) which is suitable for deposition in the deeper regions of the lungs (26).

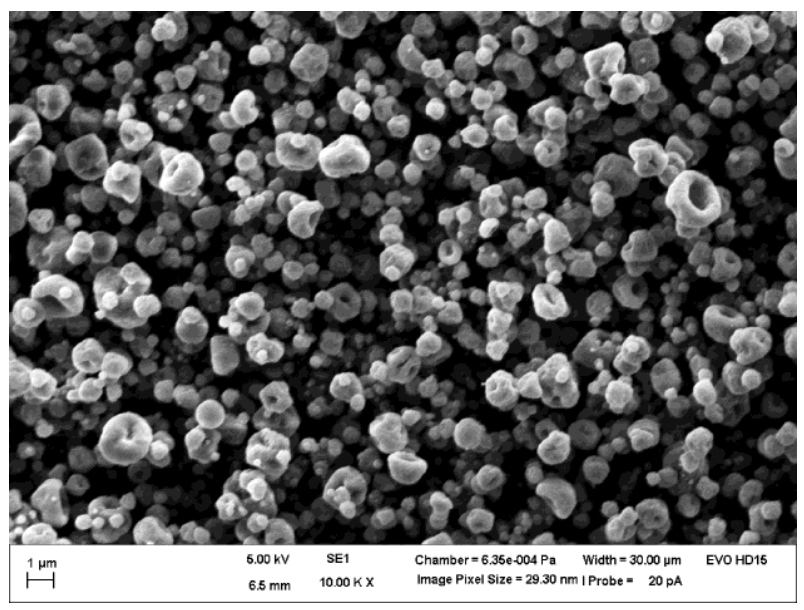

Fig. 1 Scanning electron micrographs of Clarithromycin microparticles.

The interactions between the different components of the microparticle were evaluated by DSC. Analysis was carried out for CLARI-MP, its physical mixture (PM) and raw materials. As showed in Fig. 2, clarithromycin melting and decomposition temperature were respectively, $227^{\circ} \mathrm{C}$ and $280^{\circ} \mathrm{C}$. When the drug was mixed with chitosan and leucine (PM), an early onset of endothermic peak $\left(214.8^{\circ} \mathrm{C}\right)$ was observed. Furthermore, the onset of endothermic peak of CLARI-MP sample was even lower $\left(184.5^{\circ} \mathrm{C}\right)$. 
383

384

385

386

387

393

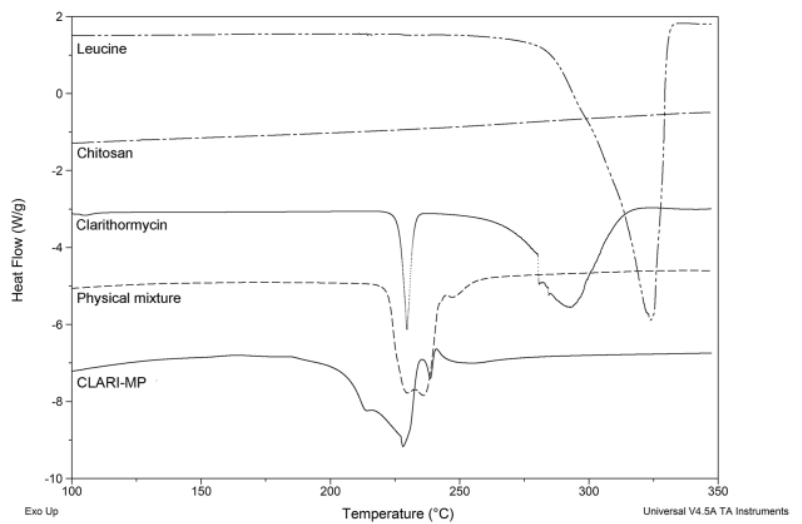

Fig. 2 DSC thermograms for the raw materials (leucine, chitosan and clarithromycin), physical mixture and clarithromycin microparticle formulation (CLARI-MP).

\section{Dissolution study}

The dissolution rate of CLARI-MP obtained by Nano Spray Dryer B-90 ${ }^{\circledR}$ was compared with CLARI raw material (Fig. 3). The release profiles were expressed as the percentage of drug release versus the time. After 30 min, more than $90 \%$ of CLARI was released in the dissolution medium, while for such release of CLARI-MP this was observed only after 60 min.

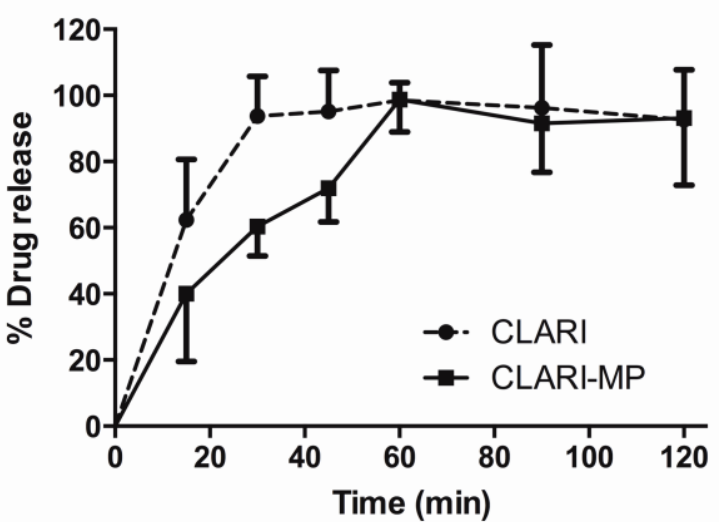

Fig. 3 Dissolution profile of clarithromycin as raw material (CLARI) and clarithromycin microparticle formulation (CLARI-MP). Each point represents the mean \pm S.D. $(n=3$, from 3 independent experiments). 
409

\section{Aerodynamic behavior}

The aerodynamic performance of microparticles is an important parameter for particle deposition in the lung. Aerosolization studies using NGI were conducted at a flow of 60 L/min during 4s (Fig. 4). The ED obtained from hypromellose capsules and dry powder inhaler was $87.5 \pm 4.4 \%$. Moreover, the percentage of particles that could be deposited in the deep lung was measured by the FPF. For particles deposited between the stages 2 and the filter (lower than $4.46 \mu \mathrm{m}$ ) the FPF was $73.3 \pm 2.3 \%$. In addition, the MMAD and the GSD of CLARI-MP were $1.81 \pm 0.14 \mu \mathrm{m}$ and $2.59 \pm 0.08$, respectively.
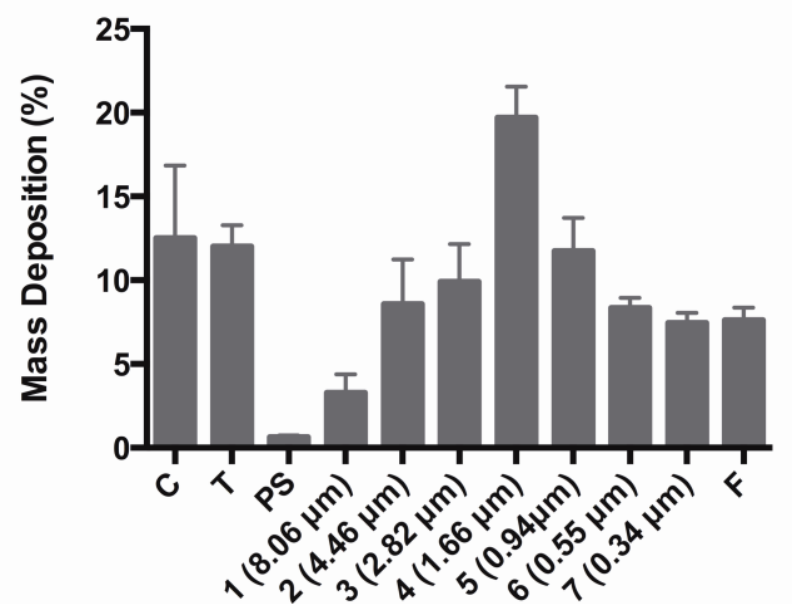

Fig. 4 Aerosol performance of clarithromycin microparticles using the Next Generator Impactor (NGI) at a flow of $60 \mathrm{~L} / \mathrm{min}$ for $4 \mathrm{~s}$. C, T, PS and F represent the percentage of particles retained in the capsule, throat, pre-separator and filter stages, respectively. Each point represents the mean \pm S.D. $(n=4$, from 2 independent experiments).

\section{In vitro CLARI-MP deposition}

CLARI-MPs deposition was carried out in the PADDOCC with capsules of CLARI-MPs, deposited in three cycles of 10 min each, using aerosolization chamber without cells. CLAR-MPs were uniform and reproducible deposited at concentration of $16.2 \pm 6.9$ $\mu \mathrm{g} / \mathrm{cm}^{2}$ of the aerosolized dose. Moreover, the total amount collected in all the three 
420 wells per capsule corresponded to $2.37 \pm 0.84 \%$ of the aerosolized dose CLARI-MPs

421 deposition. Thereafter, CLARI-MPs deposition was evaluated on Calu-3 monolayers

422 previously grown on Snapwell filter inserts. For that, aliquots of basolateral medium

423 were collected during 24h (Fig. 5A). The results show that CLARI-MPs transport across

424 the monolayer increased progressively reaching $8.7 \pm 1.7 \mu \mathrm{g} / \mathrm{cm}^{2}$.

425 Epithelial barrier property was also evaluated by TEER measurements before and after $42624 \mathrm{~h}$ of the deposition of CLARI-MPs (Fig. 5B). Before exposition in the PADDOCC, the

427 TEER of Calu-3 cells remained around $300 \Omega . \mathrm{cm}^{2}$, dropped slightly to $266.67 \pm 28.46$

$428 \Omega . \mathrm{cm}^{2}$ and were not significant different from the untreated monolayers $(248 \pm 7$

$429 \Omega . \mathrm{cm}^{2}$ ). CLARI-MPs incubated for $24 \mathrm{~h}$ in Calu-3 did not induce toxic effect, as 430 assessed with MTT assay (Fig. 5C).

431

432
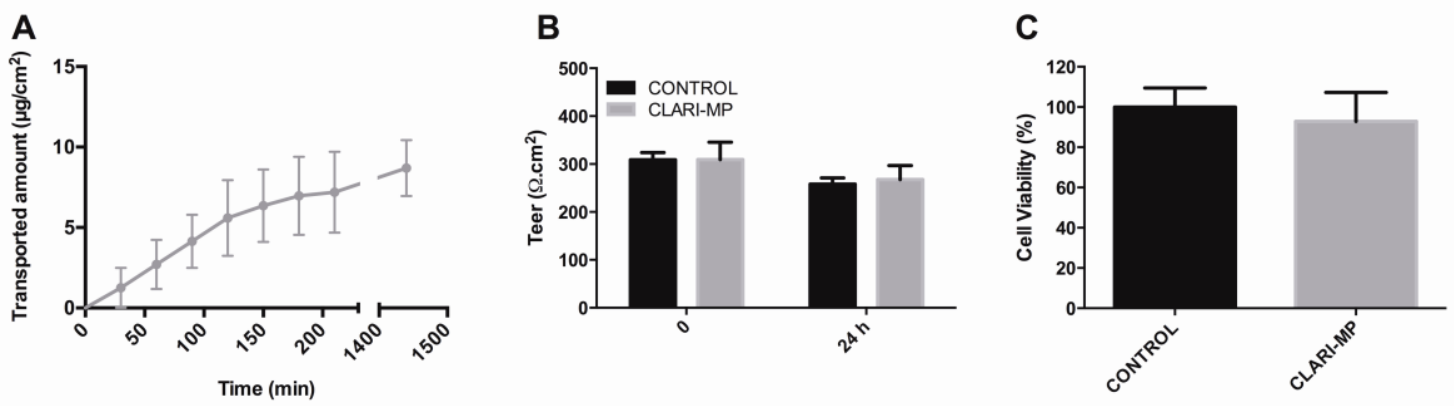

433

434 Fig. 5 Deposition of clarithromycin microparticles (CLARI-MPs) on Calu-3 monolayers using the Pharmaceutical Aerosol Deposition Device on Cell Cultures (PADDOCC)

system. (A) Drug Transport ( $n=15$, from 2 independent experiments); (B) TEER

values of Calu-3 monolayers before and after 24h of deposition of CLARI-MP; (C) Cell

viability of Calu-3 using MTT assay after 24h of deposition of CLARI-MP in the

PADDOCC; Cells without any treatment were used as CONTROL. No significant

difference was observed between the groups ( $t$-test, $p>0.05 ; \mathrm{n}=9$ from 2

independent experiments, mean \pm S.D.) 
444 Antimicrobial activity of CLARI-MP

445 The antimicrobial activity of CLARI-MPs was tested in relevant respiratory pathogens,

446 either Gram negative (Pseudomonas aeruginosa and Escherichia coli) or Gram

447 positive (Staphylococcus aureus). The results showed that the concentration of CLARI-

448 MPs needed to reduce $50 \%$ of bacterial growth was $20 \mu \mathrm{g} \mathrm{ml}^{-1}$ for $P$. aeruginosa, $6 \mu \mathrm{g}$

$449 \mathrm{ml}^{-1}$ for $E$. coli and $1 \mathrm{\mu g} \mathrm{ml}^{-1}$ for $S$. aureus. These concentrations were similar to those

450 observed in the MIC50 for the free drug (Fig 6A). As a control, drug-free microparticles

451 did not show any antibacterial activity against all strains tested (data not shown). To

452 further characterize the interaction of bacteria with MPs, the samples were processed

453 by SEM (Fig. 6B-G). Untreated P. aeruginosa and S. aureus (Fig. 6B, E, respectively)

454 showed a normal size and typical morphologies for Gram positive and negative strains.

455 After the treatment with free drug (CLARI) as well as CLARI-MPs, we observed altered

456 morphology in the bacterial population, with a melting-like network (Fig 6C-D, F-G). For

457 S. aureus we observed apoptosis-like structures, e.g. cytoplasmic blebs (Fig. 6F, G). 

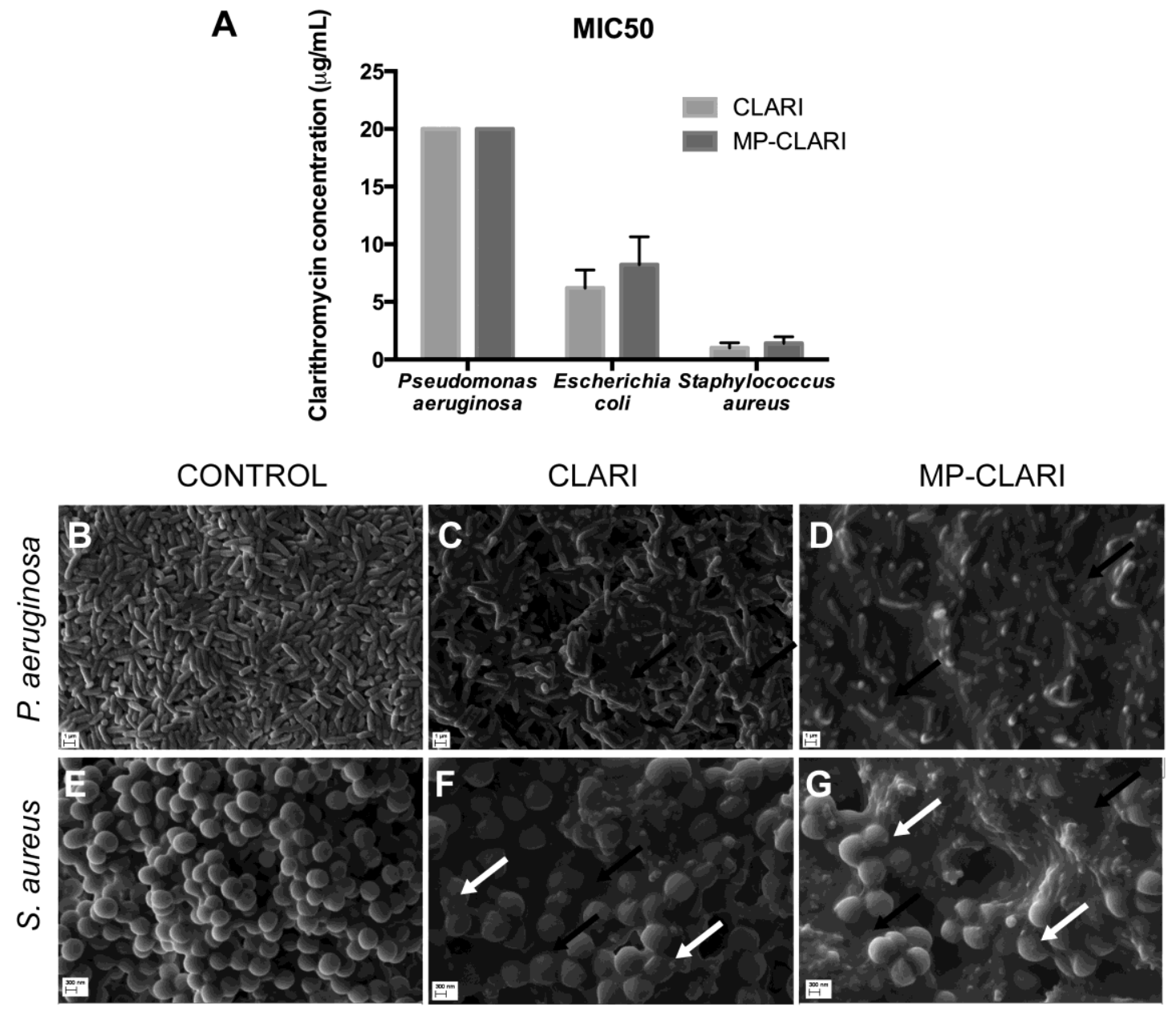

459

460 Fig. 6 (A) Minimum inhibitory concentration 50\% (MIC50) of clarithromycin solution

461 (CLARI) and clarithromycin microparticles (CLARI-MP) against $P$. aeruginosa, E. coli

462 and S. aureus; $t$-test did not show any significant differences between the two

463 formulations for either bacteria ( $p>0.05 ; n=3$ from 3 independent experiments).

464 Scanning electron micrographs (SEM) of $P$. aeruginosa (B-D) and $S$. aureus (E-G)

465 untreated $(B, E)$, or treated with free drug $(C, F)$ or CLARI-MP $(D, G)$. Examples of

466 melting-like network and apoptosis-like structures are shown with black and white

467 arrows, respectively. 


\section{DISCUSSION}

473 Drug administration via the oral route may suffer from reduced bioavailability due to the

474 pre-systemic metabolism during the passage through gut wall and liver. Therefore

475 delivering antibiotic to the lungs by inhalation could decrease adverse effects since

476 lower systemic drug concentrations are reached compared to oral delivery. However

477 after the deposition in the lungs, the drug may be eliminated by clearance systems,

478 such as mucociliarity clearance. The use of carriers systems loaded with an active

479 compound show as promise strategy to overcome clearance in the lungs. Moreover

480 such approach could also have a better anti-infective efficacy, since the particle shall

481 reach directly the infection site, and release the active compound. Here we developed

482 dry powder microparticles intended for pulmonary application, constituted by chitosan

483 and leucine, loaded with the hydrophobic antibiotic clarithromycin. With this formulation

484 we aim to improve the lung residence time, yield and FPF of the particles. Thus

485 inhalable CLARI-MPs were prepared by means of spray drying, and safety on lung

486 cells and their efficacy against gram positive and gram negative bacteria were

487 determined.

488 Chitosan, a cationic polysaccharide, has the advantage to be non-toxic and

489 biodegradable, and has already been used for the pulmonary route (27). The use of

490 chitosan avoided particle agglomeration and increase particle deposition in the

491 electrostatic particles collector. In assisting to the dry process of the particles, leucine

492 can improve powder dispersibility and aerodynamic behavior due to its ability to form

493 hollow particles with low particle density $(26,28)$. Higher concentrations of this amino

494 acid were previously reported to increase the FPF of formulations comparing to

495 lactose, the most-used excipient in antibiotic DPI formulation, without induction of

496 apparent cytotoxicity $(21,28,29)$.

497 Clarithromycin, a hydrophobic antibiotic with broad spectrum, is widely used against

498 respiratory infections (18). However as CLARI has poor solubility in water, the 
499 formation of CLAR-MPs as dry powder could improve the antibiotic activity, since it

500 enables the inhalation with maximum bioavailability and target delivery to the cells.

501 New clarithromycin microparticles or nanoparticles have already been described to

502 achieve improved delivery to the lungs, however in most of the cases only exploring

503 the pharmaceutical development $(1,3,5,21)$, without demonstrating some biological

504 properties of such formulations, which is essential to predict both efficacy and safety

505 regarding their clinical application in vivo. While antimicrobial activity has been

506 demonstrated for other CLARI formulations (30, 31), no tests regarding potential

507 toxicity on mammalian cells were performed.

508 After optimizing the processing parameters and excipients, a CLARI-MPs powder

509 formulation was obtained in high yields with excellent aerodynamic properties and

510 without suffering from the problem of incrustations at the piezoelectric nozzle as

511 reported in other studies using the Nano Spray Dryer B- $90^{\circledR}(32)$. We obtained a higher

512 yield (more than 60\%) in the process compared with other spray drying processes

513 (lower than $50 \%$ (33), mainly grace to the electrostatic particle collector. The effect of

514 the electrostatic potential difference causes an increase in the particle attraction

515 compared to the more common cyclone collector when cationic ions are presented in

516 the formulation (33).

517

518 Thermal analysis of the particles performed with DSC is a useful tool to verify

519 interactions between formulation components. We observed clarithromycin melting

520 temperature of $227^{\circ} \mathrm{C}$, as reported also by others authors (34). Importantly, we

521 observed a shift of the onset temperature for the physical mixture, and even to a

522 greater extend for CLARI-MPs, compared to the free drug, suggesting some

523 thermodynamic interaction between the components of this formulation.

524 
525 The dissolution test showed some slight delay of clarithromycin release from

526 microparticles compared to the raw material, similar to other aerosol powder

527 formulations containing different hydrophobic drugs $(35,36)$ and apparently suitable for

528 pulmonary administration. The fast dissolution rate after 60 min could be an advantage

529 to overcome clearance mechanism and optimize drug local activity.

530

531 Before deposition of CLARI-MPs to pulmonary epithelial cells, we evaluated the

532 aerodynamic behavior of aerosol particles that could be generated using hypromellose

533 capsules and a HandiHaler ${ }^{\circledR}$ by collecting them in a NGI device. The ED of the

534 formulation (about 87\%) accomplished the European pharmacopoeia specification,

535 which should be higher than $75 \%$ of the loaded dose. In addition, more than $75 \%$ of

536 the particles were deposited in stages $2-7$ (FPF). This high FPF value of DPI

537 formulation is a valuable indication of good aerosol performance when applied in vivo

538 since it is greater than $40 \%$, as recommended for antibiotic products $(26,37)$ and it is

$53955 \%$ higher than the FPF obtained for clarithromycin pMDI (3). Moreover, the MMAD

540 (about $1.9 \mu \mathrm{m}$ ) is in the range required for the deposition in deep lung (26).

541

542 The PADDOCC had been previously developed for reproducible metered deposition of

543 aerosol powders on pulmonary epithelial cell cultures under physiological conditions,

544 allowing a simulation of the complex processes of aerosol deposition and absorption in

545 vivo under controlled conditions in vitro. In this study, we used the bronchial epithelial

546 cell line Calu-3 grown at air-liquid interface conditions due to their known barrier

547 properties and easy accessibility $(23,38)$. Hein et al. 2011 showed that the deposited

548 amount of drug is directly proportional of the capsule dose using the PADDOCC (10).

549 Previous studies showed a low deposition fraction (about 1.5\%) for budesonide and

550 salbutamol sulfate using the PADDOCC and modified twin stage impinger, respectively

551 (10, 14). After deposition CLARI-MPs, we obtained a uniform deposition of

552 approximately $2.4 \%$ of total amount in the capsule. This value may appear to be low 
553 compared to the FPF $(73.3 \pm 2.3 \%)$ obtained by NGI for these particles. However, our

554 deposition result is higher than other deposition studies $(4,10,14)$. In addition, the

555 recovery of drug obtained after administered $\approx 2 \mathrm{mg}$ of clarithromycin was about 16.2

$556 \mathrm{\mu g} / \mathrm{cm}^{2}$. Considering that the cells are seeded in an area of $3.36 \mathrm{~cm}^{2}$ we could

557 speculate that the drug recover in our system correspond to $0.168 \mathrm{ng} / \mathrm{cm}^{2}$ in the lungs

$558\left(100 \mathrm{~m}^{2}\right)$, assuming the same rate of deposition (2.4\%).

559 After $24 \mathrm{~h}$ of CLARI-MP deposition, about $50 \%$ of CLARI were transported across the

560 Calu-3 epithelial barrier, suggesting that there might be also a substantial systemic

561 absorption after aerosol delivery of such microparticles. This might have advantages as

562 CLARI also has some anti-inflammatory and immune modulatory effects, according to

563 a recent paper where the compound was applied as solution-based pressurized

564 metered dose inhalers (pMDIs) (4). However the administration of clarithromycin as

565 pMDIs or nebulizers requires the use of solvents in order to solubilize it; in case of

566 CLARI-MPs as DPI no solvent exposition is required. Our results also show that the

567 epithelial barrier function was not influenced by the deposition of particles, as indicated

568 by the absence of any significant effect on TEER over 24h. Additionally CLARI-NP did

569 not induce toxic effect on Calu-3 cells, which further endorses the safety of these

570 particles.

571 Finally the efficacy of CLARI-MPs was tested on extracellular Gram positive (S.

572 aureus) and Gram negative ( $P$. aeruginosa and $E$. coli) bacteria. From the in vitro

573 evaluation our formulation maintained the same antimicrobial efficacy (MIC) as

574 observed for the free drug solubilized in DMSO. SEM results suggest that there were

575 even a higher proportion of bacteria fragments compared to the treatment with free

576 drug. A similar pattern was found for P. aeruginosa and E. coli strains, which could

577 make these extracellular bacteria more susceptible to phagocytosis and degradation by

578 macrophages.

579

580 
581

582 In this paper we described a new dry powder inhaler formulation containing

583

584

585

586

587

588

589

590

591

592

593

594

595

596

597

598

599

600

601

602

603

604

605

606

607

clarithromycin with aerodynamic particle properties suitable to reach the deep lung with safety and efficacy to kill bacteria. The formulation was easily achieved by spray drying technique in merely one step. Regarding the treatment of respiratory infections we could show a new drug delivery system efficient against both gram positive and negative bacteria, as Pseudomonas aeruginosa, Escherichia coli and Staphylococcus aureus. Importantly, we also showed an efficient deposition of clarithromycin particles on bronchial cells (Calu-3) without inducing apparent toxicity. This technology could pave the way to better DPI formulations of CLARI and other anti-infective drugs in the future.

\section{ACKNOWLEDGMENTS}

Frantiescoli Dimer is thankful to the Brazilian Coordenação de Aperfeiçoamento de Pessoal de Nível Superior (CAPES) program "Ciência sem Fronteiras" project number BEX 18215/12-2. The authors kindly thank Simone Amann for bacteria experiments, Marius Hittinger for NGI and PADDOCC experiments and Dr. Chiara Rossi for technical support of LC-MS/MS and SEM analysis.

\section{REFERENCES}

1. Park C-W, Li X, Vogt FG, Hayes Jr D, Zwischenberger JB, Park E-S, Mansour HM. Advanced spray-dried design, physicochemical characterization, and aerosol dispersion performance of vancomycin and clarithromycin multifunctional controlled release particles for targeted respiratory delivery as dry powder inhalation aerosols. Int J Pharm. 2013;455(1-2):374-392.

2. John SP, Peter RB. Inhaling medicines: delivering drugs to the body through the lungs. Nat Rev Drug Discov. 2007;6(1):67-74. 
608 3. Saadat A, Zhu B, Haghi M, King G, Colombo G, Young PM, Traini D. The

609 formulation, chemical and physical characterisation of clarithromycin-based macrolide

610 solution pressurised metered dose inhaler. J Pharm Pharmacol. 2014;66(5):639-645.

611 4. Haghi M, Saadat A, Zhu B, Colombo G, King G, Young P, Traini D.

612 Immunomodulatory Effects of a Low-Dose Clarithromycin-Based Macrolide Solution

613 Pressurised Metered Dose Inhaler. Pharm Res. 2014:1-10.

614 5. Pilcer G, Rosiere R, Traina K, Sebti T, Vanderbist F, Amighi K. New co-spray-

615 dried tobramycin nanoparticles-clarithromycin inhaled powder systems for lung

616 infection therapy in cystic fibrosis patients. J Pharm Sci. 2013;102(6):1836-1846.

617 6. Roa WH, Azarmi S, Al-Hallak MHDK, Finlay WH, Magliocco AM, Löbenberg R.

618 Inhalable nanoparticles, a non-invasive approach to treat lung cancer in a mouse

619 model. J Control Release. 2011;150(1):49-55.

620 7. Adi H, Young PM, Chan H-K, Stewart P, Agus H, Traini D. Cospray dried

621 antibiotics for dry powder lung delivery. J Pharm Sci. 2008;97(8):3356-3366.

622 8. Nandiyanto ABD, Okuyama K. Progress in developing spray-drying methods for

623 the production of controlled morphology particles: From the nanometer to

624 submicrometer size ranges. Adv Powder Technol. 2011;22(1):1-19.

625 9. Dimer FA, Durli TL, Fontana MC, Pohlmann AR, Beck RCR, Guterres SS.

626 Piezoelectric atomizing spray-dryer to convert liquids to dry powders: Operational

627 parameters and formulation characteristics. In: Tran HT, Pillai G, editors. Advances In

628 Nanotechnology \& Applictions - Volume IV: CreateSpace Independent Publishing

629 Platform; 2012. p. 105-116.

630 10. Hein S, Bur M, Schaefer UF, Lehr C-M. A new Pharmaceutical Aerosol

631 Deposition Device on Cell Cultures (PADDOCC) to evaluate pulmonary drug

632 absorption for metered dose dry powder formulations. Eur J Pharm Biopharm.

$6332011 ; 77(1): 132-138$

634 11. de Bruijne K, Ebersviller S, Sexton KG, Lake S, Leith D, Goodman R, Jetters J, 635 Walters GW, Doyle-Eisele M, Woodside R, Jeffries HE, Jaspers I. Design and testing 
636 of Electrostatic Aerosol in Vitro Exposure System (EAVES): an alternative exposure 637 system for particles. Inhal Toxicol. 2009;21(2):91-101.

638 12. Bur M, Rothen-Rutishauser B, Huwer H, Lehr C-M. A novel cell compatible 639 impingement system to study in vitro drug absorption from dry powder aerosol 640 formulations. Eur J Pharm Biopharm. 2009;72(2):350-357.

641 13. Haghi M, Traini D, Young P. In Vitro Cell Integrated Impactor Deposition 642 Methodology for the Study of Aerodynamically Relevant Size Fractions from 643 Commercial Pressurised Metered Dose Inhalers. Pharm Res. 2014;31(7):1779-1787. 644 14. Haghi M, Traini D, Bebawy M, Young PM. Deposition, Diffusion and Transport 645 Mechanism of Dry Powder Microparticulate Salbutamol, at the Respiratory Epithelia. 646 Mol Pharm. 2012;9(6):1717-1726.

647 15. Hoppentocht M, Hagedoorn P, Frijlink HW, de Boer AH. Technological and 648 practical challenges of dry powder inhalers and formulations. Adv Drug Deliv Rev. $649 \quad 2014 ; 75(0): 18-31$.

650 16. Zarogoulidis P, Kioumis I, Ritzoulis C, Petridis D, Darwiche K, Porpodis K, 651 Spyratos D, Parrish S, Browning R, Li Q, Turner JF, Freitag L, Zarogoulidis K. New 652 insights in the production of aerosol antibiotics. Evaluation of the optimal aerosol 653 production system for ampicillin-sulbactam, meropenem, ceftazidime, cefepime and 654 piperacillin-tazobactam. Int J Pharm. 2013;455(1-2):182-188.

655 17. David SR, Bergstrom RF, Bruner VL, Mitchell MI. Pharmacokinetics and 656 pharmacodynamics of IM olanzapine. Schizophr Res. 2002;53(3):183-183.

657 18. Zuckerman JM, Qamar F, Bono BR. Review of Macrolides (Azithromycin, 658 Clarithromycin), Ketolids (Telithromycin) and Glycylcyclines (Tigecycline). Med Clin 659 North Am. 2011;95(4):761-791.

660 19. Bermudez LE, Nash K, Petrofsky M, Young LS, Inderlied CB. Clarithromycin661 Resistant Mycobacterium avium Is Still Susceptible to Treatment with Clarithromycin 662 and Is Virulent in Mice. Antimicrob Agents Chemother. 2000;44(10):2619-2622. 
663 20. Global Alliance for TB Drug Development. Clarithromycin. Tuberculosis.

$664 \quad 2008 ; 88(2): 92-95$.

665 21. Moghaddam PH, Ramezani V, Esfandi E, Vatanara A, Nabi-Meibodi M, Darabi

666 M, Gilani K, Najafabadi AR. Development of a nano-micro carrier system for sustained

667 pulmonary delivery of clarithromycin. Powder Technol. 2013;239(0):478-483.

668 22. Shin J, Pauly DF, Johnson JA, Frye RF. Simplified method for determination of

669 clarithromycin in human plasma using protein precipitation in a 96-well format and

670 liquid chromatography-tandem mass spectrometry. J Chromatogr B. 2008;871(1):130-

671134.

672 23. Haghi M, Young PM, Traini D, Jaiswal R, Gong J, Bebawy M. Time- and

673 passage-dependent characteristics of a Calu-3 respiratory epithelial cell model. Drug

674 Dev Ind Pharm. 2010;36(10):1207-1214.

675 24. Hein S, Bur M, Kolb T, Muellinger B, Schaefer UF, Lehr CM. The

676 Pharmaceutical Aerosol Deposition Device on Cell Cultures (PADDOCC) in vitro

677 system: design and experimental protocol. Altern Lab Anim. 2010;38(4):285-295.

678 25. Sahner JH, Groh M, Negri M, Haupenthal J, Hartmann RW. Novel small

679 molecule inhibitors targeting the "switch region" of bacterial RNAP: Structure-based

680 optimization of a virtual screening hit. Eur J Med Chem. 2013;65(0):223-231.

681 26. Hoe S, Ivey J, Boraey M, Shamsaddini-Shahrbabak A, Javaheri E, Matinkhoo

682 S, Finlay W, Vehring R. Use of a Fundamental Approach to Spray-Drying Formulation

683 Design to Facilitate the Development of Multi-Component Dry Powder Aerosols for

684 Respiratory Drug Delivery. Pharm Res. 2014;31(2):449-465.

685 27. Grenha A, Al-Qadi S, Seijo B, Remuñán-López C. The potential of chitosan for 686 pulmonary drug delivery. J Drug Deliv Sci Tec. 2010;20(1):33-43.

687 28. Feng AL, Boraey MA, Gwin MA, Finlay PR, Kuehl PJ, Vehring R. Mechanistic

688 models facilitate efficient development of leucine containing microparticles for

689 pulmonary drug delivery. Int J Pharm. 2011;409(1-2):156-163. 
690 29. Aquino RP, Prota L, Auriemma G, Santoro A, Mencherini T, Colombo G, Russo

691 P. Dry powder inhalers of gentamicin and leucine: formulation parameters, aerosol

692 performance and in vitro toxicity on CuFi1 cells. Int J Pharm. 2012;426(1-2):100-107.

693 30. Mohammadi G, Nokhodchi A, Barzegar-Jalali M, Lotfipour F, Adibkia K, Ehyaei

$694 \mathrm{~N}$, Valizadeh H. Physicochemical and anti-bacterial performance characterization of

695 clarithromycin nanoparticles as colloidal drug delivery system. Colloids and Surfaces B:

696 Biointerfaces. 2011;88(1):39-44.

697 31. Valizadeh H, Mohammadi G, Ehyaei R, Milani M, Azhdarzadeh M, Zakeri-Milani

698 P, Lotfipour F. Antibacterial activity of clarithromycin loaded PLGA nanoparticles.

699 Pharmazie. 2012;67(1):63-68.

700 32. Schmid K, Arpagaus C, Friess W. Evaluation of the Nano Spray Dryer B-90 for

701 pharmaceutical applications. Pharm Dev Technol. 2011;16(4):287-294.

702 33. Durli TL, Dimer FA, Fontana MC, Pohlmann AR, Beck RC, Guterres SS.

703 Innovative approach to produce submicron drug particles by vibrational atomization

704 spray drying: influence of the type of solvent and surfactant. Drug Dev Ind Pharm.

7052013.

706 34. Gomez-Burgaz M, Torrado G, Torrado S. Characterization and superficial

707 transformations on mini-matrices made of interpolymer complexes of chitosan and

708 carboxymethylcellulose during in vitro clarithromycin release. Eur J Pharm Biopharm.

$7092009 ; 73(1): 130-139$.

710 35. Beck-Broichsitter M, Schweiger C, Schmehl T, Gessler T, Seeger W, Kissel T.

711 Characterization of novel spray-dried polymeric particles for controlled pulmonary drug

712 delivery. J Control Release. 2012;158(2):329-335.

713 36. Lee SH, Teo J, Heng D, Zhao Y, Ng WK, Chan HK, Tan RB. Steroid-decorated

714 antibiotic microparticles for inhaled anti-infective therapy. J Pharm Sci.

$715 \quad 2014 ; 103(4): 1115-1125$.

716 37. Belotti S, Rossi A, Colombo P, Bettini R, Rekkas D, Politis S, Colombo G,

717 Balducci AG, Buttini F. Spray dried amikacin powder for inhalation in cystic fibrosis 
718 patients: A quality by design approach for product construction. Int J Pharm.

1

2

3

4

5

6
$719 \quad 2014 ; 471(1-2): 507-515$.

720 38. Grainger Cl, Greenwell LL, Lockley DJ, Martin GP, Forbes B. Culture of Calu-3

721 cells at the air interface provides a representative model of the airway epithelial barrier.

722 Pharm Res. 2006;23(7):1482-1490.

723

724

725 


\section{Legend to Figures}

727 Fig. 1 Scanning electron micrographs of Clarithromycin microparticles.

728 Fig. 2 DSC thermograms for the raw materials (leucine, chitosan and clarithromycin), physical mixture and clarithromycin microparticle formulation (CLARI-MP).

Fig. 3 Dissolution profile of clarithromycin as raw material (CLARI) and clarithromycin microparticle formulation (CLARI-MP). Each point represents the mean \pm S.D. $(n=3$, from 3 independent experiments).

Fig. 4 Aerosol performance of clarithromycin microparticles using the Next Generator Impactor (NGI) at a flow of $60 \mathrm{~L} / \mathrm{min}$ for $4 \mathrm{~s}$. C, T, PS and F represent the percentage of particles retained in the capsule, throat, pre-separator and filter stages, respectively.

D. ( $n=4$, from 2 independent experiments).

Fig. 5 Deposition of clarithromycin microparticles (CLARI-MPs) on Calu-3 monolayers using the Pharmaceutical Aerosol Deposition Device on Cell Cultures (PADDOCC) system. (A) Drug Transport ( $n=15$, from 2 independent experiments); (B) TEER respectively. viability of Calu-3 using MTT assay after $24 \mathrm{~h}$ of deposition of CLARI-MP in the PADDOCC; Cells without any treatment were used as CONTROL. $t$-test did not show any significant differences $(p>0.05 ; \mathrm{n}=9$ in 2 independent experiments, mean \pm S.D.) Fig. 6 (A) Minimum inhibitory concentration 50\% (MIC50) of clarithromycin solution (CLARI) and clarithromycin microparticles (CLARI-MP) against $P$. aeruginosa, E. coli and $S$. aureus; $t$-test did not show any significant differences between the two formulations for either bacteria ( $p>0.05 ; \mathrm{n}=3$ independent experiments). Scanning electron micrographs (SEM) of $P$. aeruginosa (B-D) and $S$. aureus (E-G) untreated $(B, E)$, or treated with free drug $(C, F)$ or MP-CLARI $(D, G)$. Examples of melting-like network and apoptosis-like structures are shown with black and white arrows, 


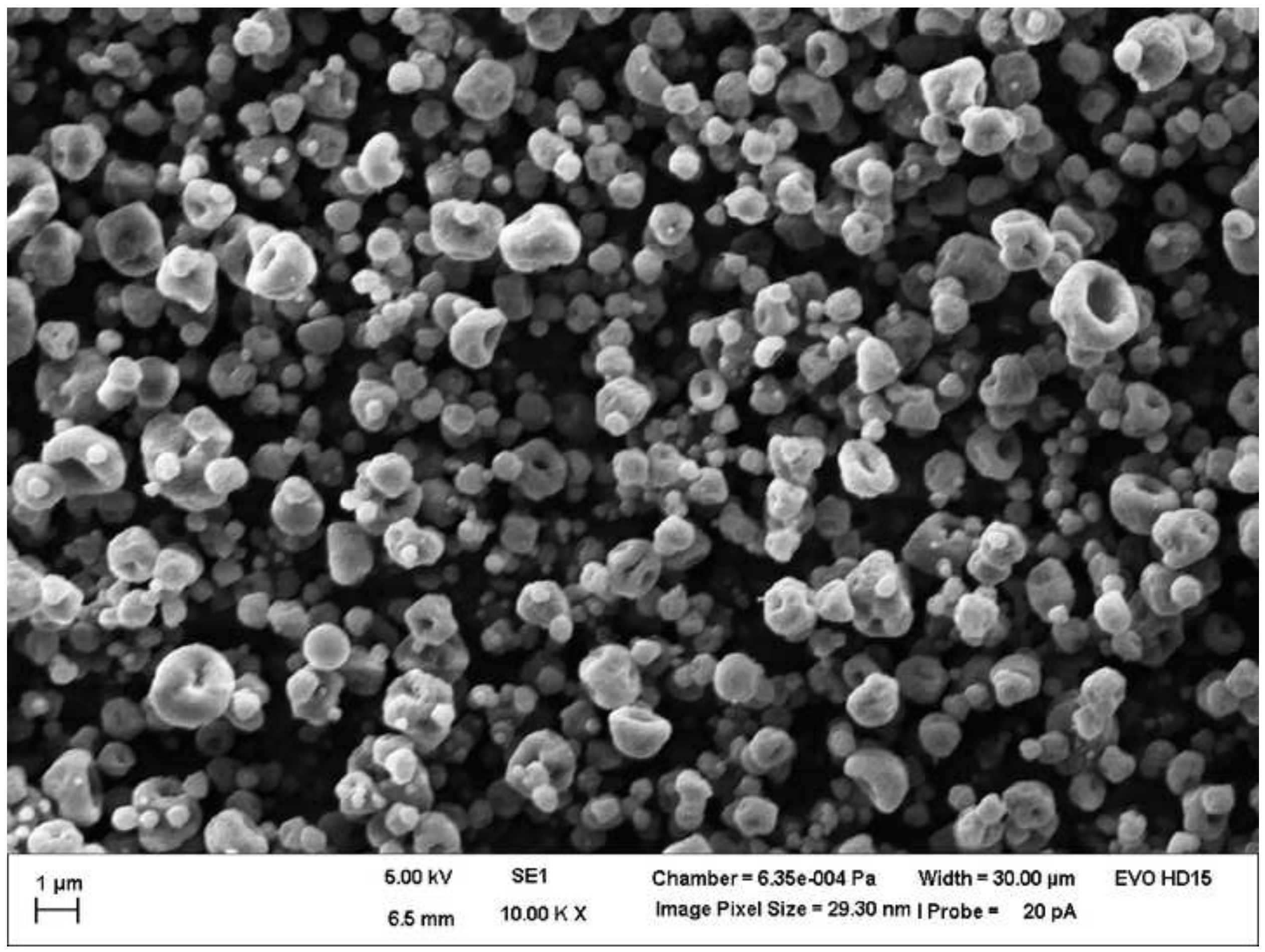


Click here to download high resolution image

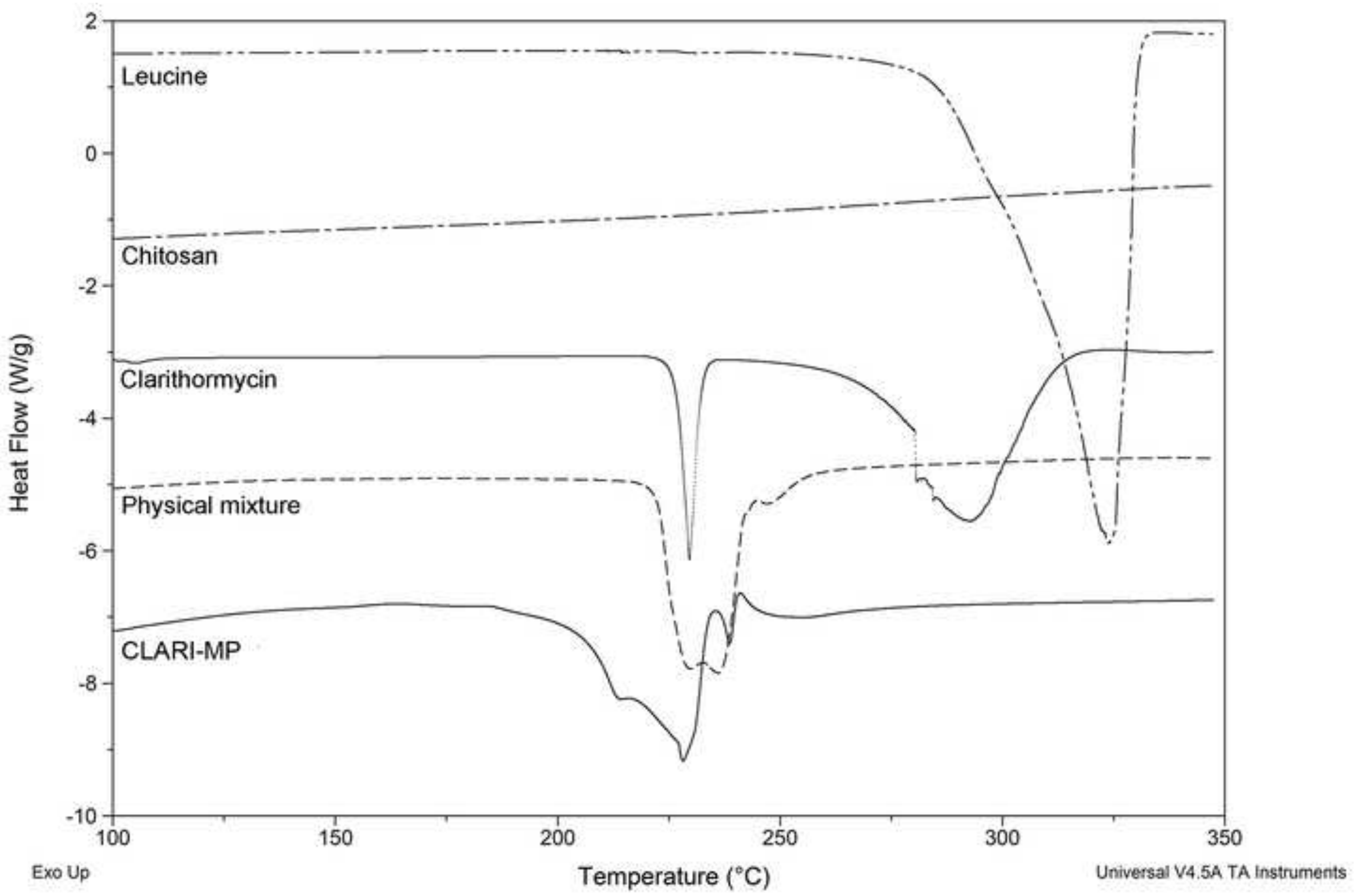




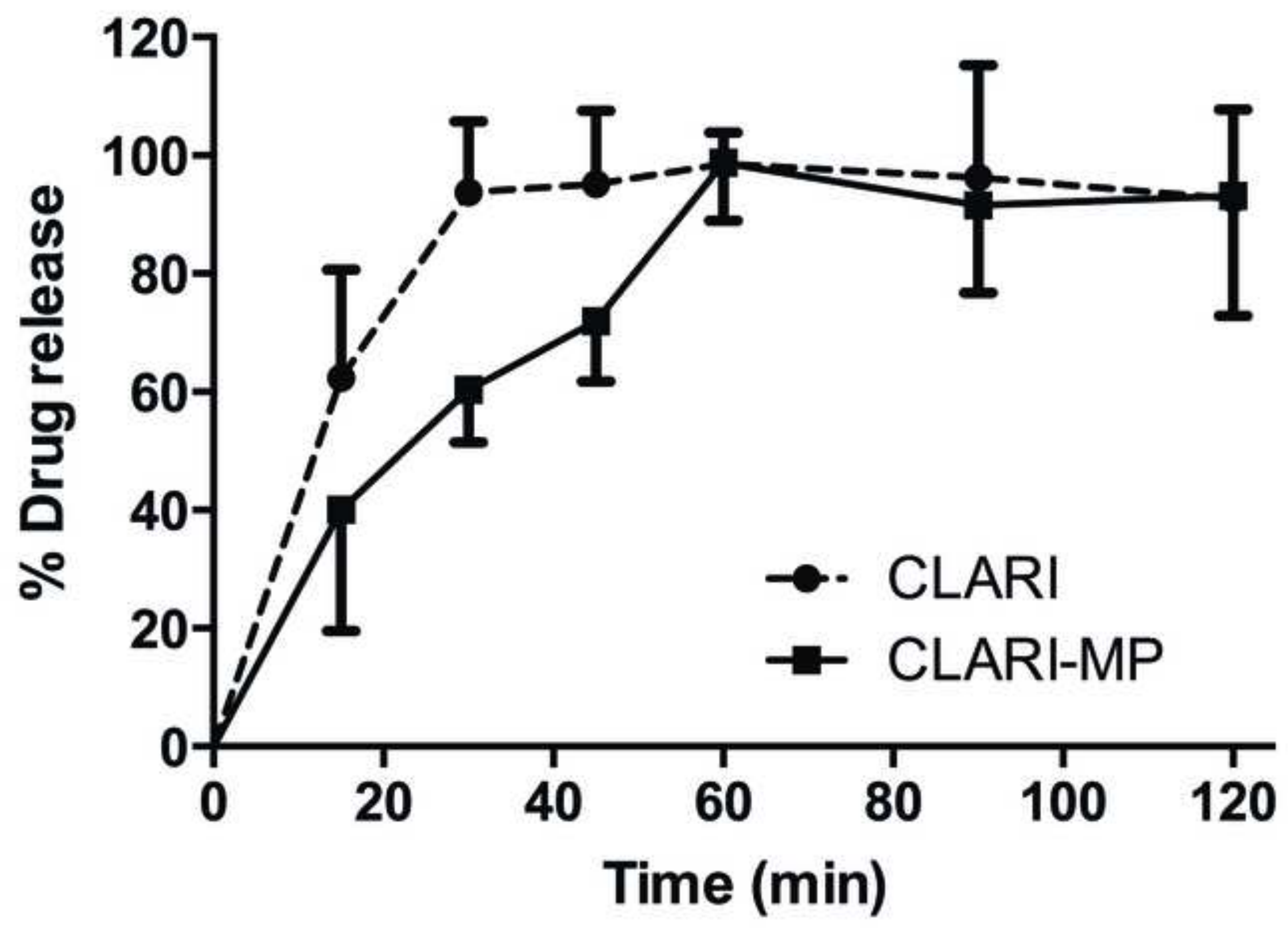




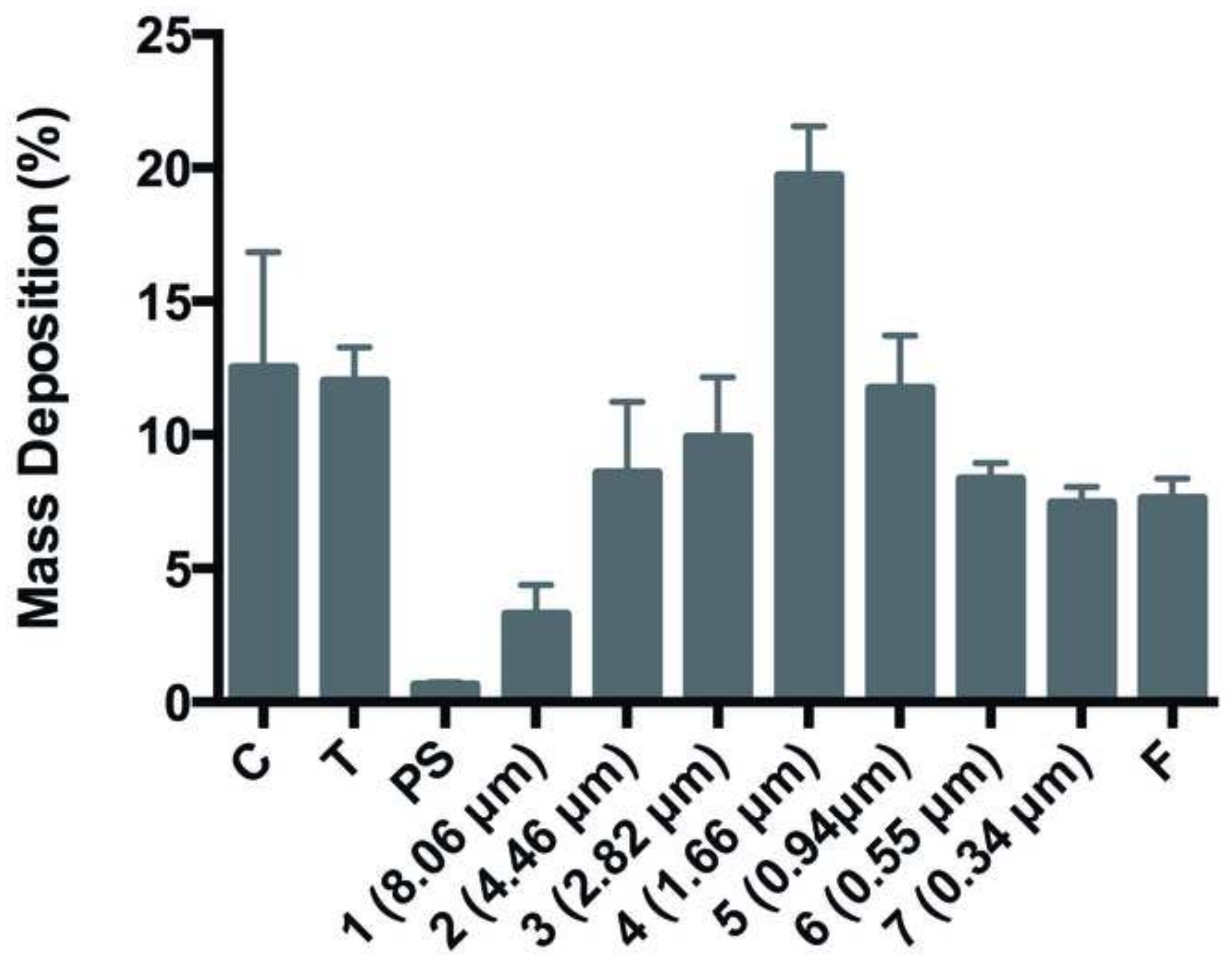



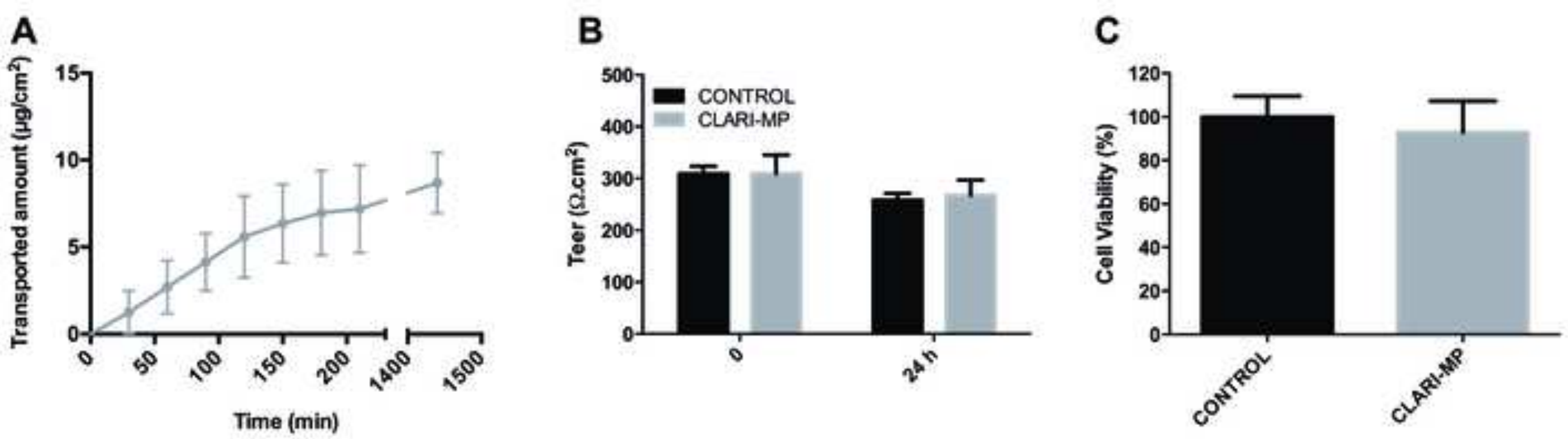

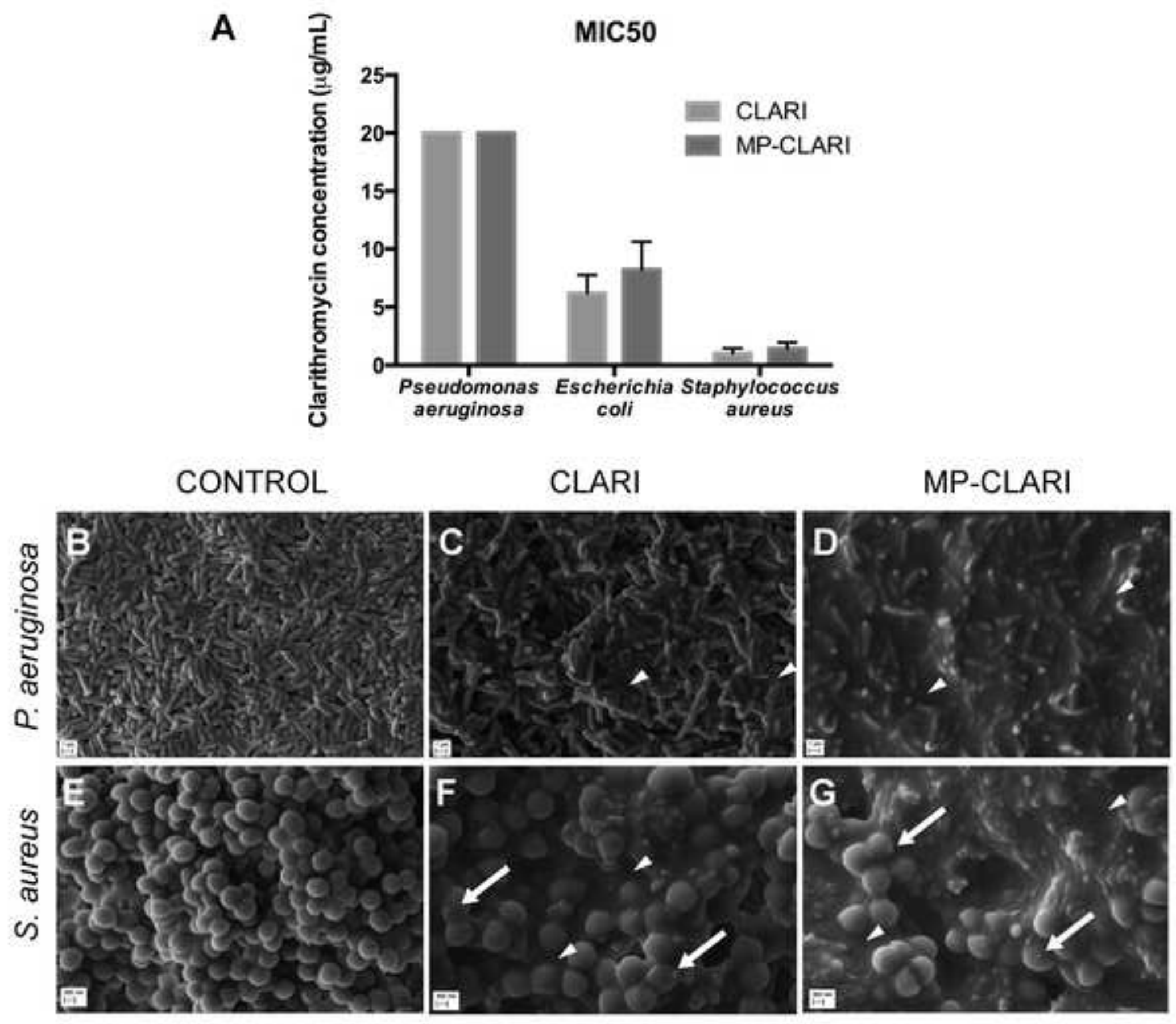